\title{
Breast screening with magnetic resonance imaging
}

\author{
Anabel Scaranelo MD PhD
}

See also practice article by Warner and colleagues at www.cmaj.ca/lookup/doi/10.1503/cmaj.120392

\section{Breast screening with magnetic resonance imaging (MRI) is supplementary to mammography}

The availability of MRI as a supplementary examination to mammography offers a clear clinical benefit to some women at high risk for breast cancer. ${ }^{1-5}$ In a meta-analysis of 11 studies, MRI had a significantly higher sensitivity than mammography when used in dense breasts. ${ }^{1}$ However, MRI is not meant to replace mammography. Some cancers, such as ductal carcinoma in situ, may be detected by mammography but not by MRI. ${ }^{2}$
Breast screening with MRI should be offered to patients at high risk

Several guidelines ${ }^{2-5}$ recommend annual supplemental screening with MRI for women who are at high risk for breast cancer (lifetime risk 20\%$25 \%$ or more). This includes women who carry mutations of the $B R C A$ genes, their first-degree untested relatives, and women who received radiation to the chest between the ages of 10 and 30 years (e.g., treatment for Hodgkin lymphoma). Expert consensus does not currently support supplemental MRI screening for women with a lifetime risk of breast cancer that is less than $15 \%$. There is considerable uncertainty over the use of MRI screening for women with intermediate risk (15\%-20\%), including those with dense breasts or a previous diagnosis of atypia (e.g., lobular carcinoma in situ, atypical lobular hyperplasia, atypical ductal hyperplasia) on breast biopsy. ${ }^{2,3}$
Tools are available to determine who is at high risk

Prediction models are constantly evolving. Although all have limitations, a particularly comprehensive tool to assess lifetime risk has been developed by the International Breast Cancer Intervention Study (available at www .ems-trials.org/riskevaluator/). No model currently includes breast density on mammography as a covariate. Referral to a genetics or breast cancer clinic is useful in clarifying risk.

\section{References}

1. Warner E, Messersmith H, Causer P, et al. Systematic review: using magnetic resonance imaging to screen women at high risk for breast cancer. Ann Intern Med 2008;148:671-9.

2. Lee CH, Dershaw DD, Kopans D, et al. Breast cancer screening with imaging: recommendations from the Society of Breast Imaging and the ACR on the use of mammography, breast MRI, breast ultrasound, and other technologies for the detection of clinically occult breast cancer. J Am Coll Radiol 2010;7:18-27.

3. Saslow D, Boetes C, Burke W, et al.; American Cancer Society Breast Cancer Advisory Group. American Cancer Society guidelines for breast screening with MRI as an adjunct to mammography. CA Cancer J Clin 2007;57:75-89.

4. Mann RM, Kuhl CK, Kinkel K, et al. Breast MRI: guidelines from the European Society of Breast Imaging. Eur Radiol 2008;18:1307-18.
The best time for MRI is during the second week of the menstrual cycle

Because normal breast tissue may interfere with accurately interpreting the MRI study, the timing of imaging during the menstrual cycle is important. ${ }^{4}$
A single screening MRI may be considered for women with newly diagnosed breast cancer

Guidelines recommend that women with newly diagnosed breast cancer (particularly lobular-type breast cancer) and a normal examination of the contralateral breast by conventional imaging (mammography or ultrasound) and clinical palpation should receive a single screening MRI of the contralateral breast at the time of diagnosis. ${ }^{2}$
5. Sardanelli F, Boetes C, Borisch B, et al. Magnetic resonance imaging of the breast: recommendations from the EUSOMA working group. Eur J Cancer 2010;46:1296-316.

Competing interests: None declared.

This article has been peer reviewed.

Affiliations: From the Medical Imaging Department, Princess Margaret Hospital, and the Marvelle Koffler Breast Centre, Mount Sinai Hospital, Toronto, Ont.

Correspondence to: Anabel Scaranelo, anabel .scaranelo@uhn.ca

CMAJ 2012. DOI:10.1503/cmaj.110008 